\title{
Admission of patients with infectious disease at the medical admissions ward, Sygehus Thy-Mors - quality-goals
}

\author{
Rita Vosyliene
}

From 4th Danish Emergency Medicine Conference

Roskilde, Denmark. 25-26 November 2011

\section{Background}

In the Electronic Patient Charts at Sygehus Thy-Mors (STM) there is no recording of patient arrival-time, admission-time or time of treatment-start. This makes establishing quality-goals difficult.

\section{Methods}

This study analyses admissions with infectious diseases in the period Jan-Feb 2010 to the medical admissions ward at STM. Especially with respect to establishing quality-goals, for the admission of these patients.

\section{Results}

The study included 93 patients admitted with infections regardless of the suspected diagnosis at the time of referral. It was found that there was a large discrepancy between suspected diagnosis and diagnosis found at the hospital. 58\% was admitted with a suspected infection. $63 \%$ of the patients over 71 years where admitted with a suspected diagnosis other than infection, i.e. dehydration, apoplexy etc. There where no records of suspicion of SIRS or evaluation of sepsis-criteria even though $54 \%$ of the patients matched the criteria. The conclusion is that sepsis and SIRS are grossly underestimated during admission of especially elderly patients with vague symptoms. ABG was ordered in $42 \%$ of cases, lactate in $6 \%$. ABG is most frequently ordered in suspected pneumonia or COPD.

\section{Conclusion}

The study establishes three quality-goals: 1) Immediate assessment of SIRS-criteria upon pt's arrival - especially

Correspondence: rivo@rn.dk

Sygehus Thy-Mors Hospital, Denmark

Submit your next manuscript to BioMed Central and take full advantage of:

- Convenient online submission

- Thorough peer review

- No space constraints or color figure charges

- Immediate publication on acceptance

- Inclusion in PubMed, CAS, Scopus and Google Scholar

- Research which is freely available for redistribution 